\title{
Promising candidate cerebrospinal fluid biomarkers of seizure disorder, infection, inflammation, tumor, and traumatic brain injury in pediatric patients
}

\author{
Seh Hyun Kim, MD, $\mathrm{PhD}^{1}$, Soo Ahn Chae, MD, $\mathrm{PhD}^{1,2}$ \\ ${ }^{1}$ Department of Pediatrics, Chung-Ang University Hospital, Seoul, Korea; ${ }^{2}$ College of Medicine, Chung-Ang University, Seoul, Korea
}

Cerebrospinal fluid (CSF) is a dynamic metabolically active body fluid that has many important roles and is commonly analyzed in pediatric patients, mainly to diagnose central nervous system infection and inflammation disorders. CSF components have been extensively evaluated as biomarkers of neurological disorders in adult patients. Circulating microRNAs in CSF are a promising class of biomarkers for various neurological diseases. Due to the complexity of pediatric neurological disorders and difficulty in acquiring CSF samples from pediatric patients, there are challenges in developing CSF biomarkers of pediatric neurological disorders. This review aimed to provide an overview of novel CSF biomarkers of seizure disorders, infection, inflammation, tumor, traumatic brain injuries, intraventricular hemorrhage, and congenital hydrocephalus exclusively observed in pediatric patients.

Key words: Biomarker, Cerebrospinal fluid, MicroRNA, Neurologic disorder, Pediatric patient

\section{Key message}

- Pediatric cerebrospinal fluid (CSF) components have been extensively evaluated as biomarkers of various neurologic diseases.

- Several promising candidate CSF biomarkers, including Tau, glial fibrillary acidic protein, neuron-specific enolase, $S 100 \beta$, and interleukins, have been studied in pediatric patients with seizure disorders, central nervous system infections, inflammation, tumors, hypoxic-ischemic encephalopathy, traumatic brain injuries, intraventricular hemorrhage, and congenital hydrocephalus.

- Circulating microRNAs in the CSF are a promising class of biomarkers for various neurological diseases.

\section{Introduction}

Cerebrospinal fluid (CSF) analysis has been widely used to diagnose or exclude central nervous system (CNS) infection dis- orders. These CSF examinations include CSF/serum albumin ratio, cell count, immunoglobulin (Ig) G (IgG), IgM, lactate, and culture. ${ }^{1)}$ In addition, because disorders of intracranial pressure can result in sudden or progressive headache, CSF pressure has been used to evaluate headache. ${ }^{2)}$ Intracranial hypertension and hypotension syndromes can cause headaches. ${ }^{2}$ The intraventricular catheter method is the gold standard measurement for determining intracranial pressure. However, lumbar puncture (LP) is less invasive. ${ }^{3)}$ Although rare in children, headache can occur as a complication of LP. ${ }^{4}$ The correct analysis of CSF is crucial in diagnosing infectious and inflammatory conditions including the brain, spinal cord, and meninges. Because of the close proximity between the CSF and the brain, CSF is a good source for biomarkers that reflect pathological processes within the CNS. ${ }^{1)}$

Since CSF is more easily acquired in adult patients than pediatric patients by LP, CSF components have been extensively evaluated as biomarkers of neurologic disorder including Alzheimer disease, amyotrophic lateral sclerosis, traumatic brain injury (TBI), and adult-onset normal-pressure hydrocephalus. $\left.{ }^{5-9}\right)$ However, because of the invasiveness of LP, it is difficult to acquire CSF from pediatric patients and almost impossible to acquire CSF from a healthy child. This makes it difficult to identify CSF biomarkers for pediatric neurological disorders. MicroRNAs (miRNAs) in the CSF were recently shown to be a promising class of biomarkers for various neurological diseases, including CNS tumors, Alzheimer disease, multiple sclerosis (MS), Parkinson disease, and status epilepticus. ${ }^{10-14)}$ These miRNAs and short interfering RNAs are well-known small RNAs that play a major role in RNA interference. ${ }^{15)}$ In particular, miRNAs are endogenous single-stranded noncoding RNAs with 18-23 nucleotides capable of playing important roles in targeting mRNAs for cleavage or translational repression. ${ }^{16,17)}$ Altered levels of circulating miRNAs have been seen in many diseases. ${ }^{18,19)}$ Also, miRNAs mostly function in the intracellular compartment, although cell-free circulating miRNAs have been detected in most extracellular fluids, including the CSF.20) Although only a few CSF studies in pediatric patients to date have aimed to identify biomarkers for diagnosing and managing neurological 


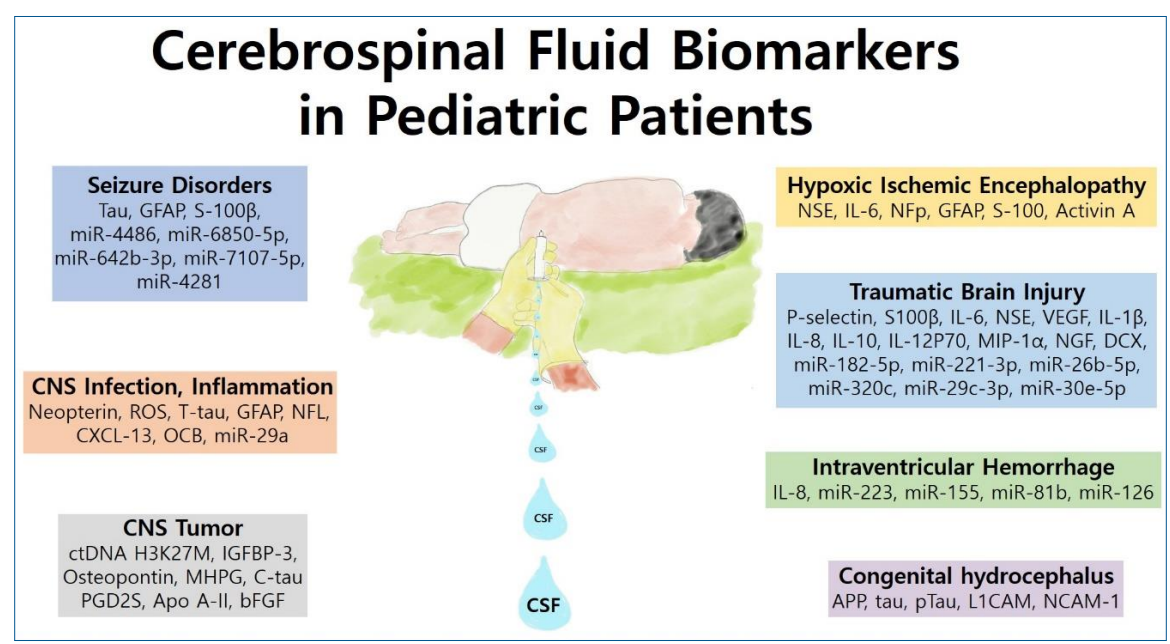

Graphical abstract. Summary of cerebrospinal fluid (CNS) biomarkers of neurologic disorders in pediatric patients.

disorders, various other studies are beginning to emerge. Only a few comprehensive review articles to date have reported on CSF analyses of pediatric neurological disorders. This review will focus on promising candidate CSF biomarkers of neurological disorders exclusively observed in pediatric patients.

\section{CSF sampling, preparation, storage, and interpretation}

CSF is a dynamic metabolically active body fluid that has many important roles. ${ }^{21)}$ The CSF is an ultrafiltrate of plasma that is normally composed of $99 \%$ water. ${ }^{22)}$ It also contains electrolytes, glucose, enzymes, proteins, and a few white blood cells. ${ }^{22)}$ CSF fills the subarachnoid space; in children aged 4-13 years, the static CSF volume is $65-150 \mathrm{~mL} .^{21)}$ The neonate choroid plexus produces approximately $25 \mathrm{~mL} /$ day of CSF, while the circulating volume is approximately $50 \mathrm{~mL}{ }^{23)}$ The CSF production rate reaches $14-36 \mathrm{~mL} / \mathrm{hr}$, and the total volume increases to approximately $150 \mathrm{~mL}$ in adults. ${ }^{21)}$ It is crucial to precisely analyze CSF samples to acquire valid information. ${ }^{1)}$ Using low-absorbing polypropylene tubes is recommended and because there is a craniocaudal gradient for some CSF biomarkers, and it is necessary to collect a standardized volume of CSF.") Changes in the proteome have been observed in uncentrifuged CSF samples left at room temperature for as few as 30 minutes. ${ }^{24)}$ The recom. mended ideal spinning centrifugation condition is spinning at $2,000 \times \mathrm{g}$ for 10 minutes, preferably in a cooled condition, or $400-450 \times \mathrm{g}$ when the cells are to be preserved for analysis. ${ }^{25}$ ) Time must be minimized for transport to the laboratory and the samples must be cooled on ice during transport. ${ }^{25)}$ Blood contamination can disturb the interpretation of samples; thus, traumatic LP should be avoided by not overshooting the needle insertion, as there is an extensive venous plexus lining the ventral wall of the subarachnoid space. ${ }^{1)}$ If trauma occurs during the LP, the CSF sample must be centrifuged immediately and the clear CSF transferred to a new tube. ${ }^{1)}$ Interpreting CSF biomarkers is complicated in pediatric patients, especially those in the first year of life, because age reference values are different. CSF levels of tau, glial fibrillary acidic protein (GFAP), and the CSF/albumin ratio is known to differ among ages due to normal development of the CNS. ${ }^{26)}$ Protein concentrations of CSF are higher in new. borns and older adults, lowest in children, and increase again in adolescence and adulthood. ${ }^{27)}$

\section{CSF biomarkers of pediatric neurological disorders}

\section{Seizure disorders}

Tau is a marker associated with axonal degeneration and widely used in dementia investigations. ${ }^{1)}$ Tau protein is typically found in cortical axons and stabilizes microtubules. ${ }^{28)}$ Elevated total tau level in the CSF was observed in pediatric patients with acute encephalopathy with biphasic seizures but not in those without encephalopathy and only febrile seizures. ${ }^{29)}$ Tau levels are high in newborn infants, possibly due to neuroaxonal plasticity, and decrease during the first years of life. ${ }^{26)}$ Elevated CSF levels of GFAP and S-100 calcium-binding protein beta (S-100ß) were found in children with seizures (Table 1). ${ }^{29-31)}$ GFAP is an intermediate filament protein that is produced in astrocytes and ependymal cells of the CNS. ${ }^{32}$ GFAP in the CSF is increased in children with white-matter disorders and can be measured to track gliosis. ${ }^{33)} \mathrm{S}-100 \beta$ is also a glial marker that is expressed by astrocytes and promotes astrocyte proliferation, neuritis growth, and neuronal development. ${ }^{1,34)}$

Few studies have shown a relationship between seizures and CSF miRNA. Furthermore, febrile seizure patients displayed higher CSF exosomal miRNA profiles than controls, and these altered miRNA profiles appeared related to complex febrile seizures. $^{35)}$ These highly expressed miRNAs included miR-4486, miR-6850-5p, miR-642b-3p, miR-7107-5p, and miR-4281 (Table 1). ${ }^{35)}$ 


\section{CNS infection and inflammation}

$\mathrm{CSF} /$ serum albumin ratio and CSF cell counts, culture, lactate, and $\operatorname{IgG}$ or IgM measurements are basic CSF tests that have been used to diagnose infectious and inflammatory CNS disorders. ${ }^{1)}$ To define the etiology of CNS infections, next-generation sequencing is gradually being tested in CSF samples of pediatric patients with encephalitis, meningoencephalitis, and meningitis. ${ }^{36)} \mathrm{How}$. ever, the diagnostic value of next-generation sequencing of the CSF of pediatric patients is difficult to quantify. ${ }^{36}$ One observational retrospective study analyzed 3 CSF biomarkers including neopterin, total proteins, and leukocytes in pediatric patients with neuroinflammatory disorders including viral meningoencephalitis, bacterial meningitis, and acquired-immune mediated disorders (Table 2). ${ }^{37}$ In the canonical discriminant analysis of these 3 biomarkers, the value of CSF neopterin was the highest in the viral and bacterial infection groups. ${ }^{37)}$ Neopterin is known to be elevated under inflammatory conditions and independently produced in the brain. ${ }^{38-40)}$ It has been suggested that microglia and astrocytes produce neopterin since these cells respond to interferon-gamma. ${ }^{40)}$ Peripheral neurons including dorsal root ganglia neurons also produce neopterin under inflammatory conditions. ${ }^{40)}$ An increased level of neopterin in the CSF has been reported in several diseases including acute bacterial and viral infections and chronic neuroinflammatory diseases. ${ }^{38,39,41,42)}$

One study assessed the validity of CSF oxidative status in pediatric patients with CNS diseases. ${ }^{43)}$ A total of 87 pediatric patients were enrolled in the study, and the mean level of reactive oxygen species in the bacterial meningitis group was significantly higher than that of the other infection-associated group. ${ }^{43)} \mathrm{An}$ other study analyzed total tau, GFAP, and neurofilament light (NFL) levels in CSF of pediatric patients. ${ }^{44}$ This study showed that total tau, GFAP, and NFL levels were increased in patients with infectious and inflammatory CNS disorders compared with controls. ${ }^{45)} \mathrm{NFL}$ is a structural protein that is rich in myelinated axons and elevation of NFL is a indicator of white matter axonal injury. ${ }^{33)}$

A study of 122 children with tuberculous meningitis showed that miR-29a expression in the peripheral blood and CSF was increased compared with the control group. ${ }^{46)}$ The authors sug. gested that the miR-29a level of the peripheral blood and CSF could be a biomarker for diagnosing tuberculous meningitis. ${ }^{46)}$

CSF studies in acute disseminated encephalomyelitis (ADEM) are notable for their lack of confirmatory features. ${ }^{47)} \mathrm{CSF}$ leukocyte counts have are reportedly normal in $42 \%-72 \%$ of pediatric patients with ADEM. ${ }^{47)}$ Pleocytosis is typically mild, with a high percentage of lymphocytes and monocytes. ${ }^{48,49)}$ An elevated CSF

Table 1. Summary of pediatric CSF novel biomarkers for seizure disorders

CSF, cerebrospinal fluid; GFAP, glial fibrillary acidic protein; miR, microRNA; S-100ß, S-100 calcium-binding protein beta.

Table 2. Summary of pediatric CSF biomarkers of novel CNS infections and inflammatory states

\begin{tabular}{|c|c|c|c|c|}
\hline Biomarker & Source & Age & No. & Interpretation \\
\hline \multirow[t]{4}{*}{ Neopterin } & Dale et al. ${ }^{38)}$ & $1 \mathrm{mo}-15 \mathrm{yr}$ & 158 & $\begin{array}{l}\text { CSF neopterin was elevated in acute encephalitis and with other acute } \\
\text { inflammatory CNS disorders. }\end{array}$ \\
\hline & Molero-Luis et al. ${ }^{39)}$ & $1 \mathrm{mo}-19 \mathrm{yr}$ & 606 & $\begin{array}{l}\text { Neuropediatric patients with inflammatory-immune mediated processes had } \\
\text { significantly higher CSF neopterin, protein and leukocyte values than the } \\
\text { other groups. }\end{array}$ \\
\hline & Macdonald-Laurs et al. ${ }^{41)}$ & $0-14 \mathrm{yr}$ & 10 & CSF neopterin was elevated children with influenza-associated encephalopathy. \\
\hline & Casas-Alba et al. ${ }^{42)}$ & 1 yr 7 mo-2 yr 2 mo & 36 & $\begin{array}{l}\text { CSF neopterin was increased in children with presence of inflammatory lesions } \\
\text { on MRI. }\end{array}$ \\
\hline ROS & Yamanaka et al. ${ }^{43)}$ & $7.4 \pm 4.6 \mathrm{yr}$ & 8 & $\begin{array}{l}\text { ROS level in the bacterial meningitis group were higher than in other infection- } \\
\text { associated groups. }\end{array}$ \\
\hline $\begin{array}{l}\text { T-tau, GFAP, } \\
\text { NFL }\end{array}$ & Shahim et al. ${ }^{44)}$ & $1 y-16 y r$ & 607 & $\begin{array}{l}\text { T-tau, GFAP, and NFL were increased in infectious and inflammatory central } \\
\text { nervous system disorders compared with controls. }\end{array}$ \\
\hline miR-29a & Pan et al. ${ }^{46)}$ & $1 y-8 y r$ & 112 & MiR-29a expressions in CSF were increased in pediatric tuberculous meningitis. \\
\hline CXCL-13 & Galardi et al. ${ }^{57)}$ & NA & 24 & $\begin{array}{l}\text { All noninflammatory controls had low levels of CXCL-13 while } 40 \% \text { of ADEM, } \\
22.2 \% \mathrm{CIS} \text { and } 62.5 \% \text { of MS children had high levels of CXCL-13. }\end{array}$ \\
\hline OCB & Sinclair et al. ${ }^{54)}$ & 2 mo-15 yr 10 mo & 200 & $\begin{array}{l}\text { Intrathecal OCBs were found in } 19 \% \text { of those with inflammatory CNS disorders } \\
\text { compared with none of the } 142 \text { patients with noninflammatory CNS disorders. }\end{array}$ \\
\hline
\end{tabular}

CSF, cerebrospinal fluid; CNS, central nervous system; MRI, magnetic resonance imaging; ROS, reactive oxygen species; T-tau, total tau; GFAP, glial fibrillary acidic protein; NFL, neurofilament light; miR, microRNA; CXCL-13, chemokine (C-X-C motif) ligand 13; OCB, oligoclonal band; ADEM, acute disseminated encephalomyelitis; CIS, clinically isolated syndrome; NA, not applicable; MS, multiple sclerosis. 
IgG level has been reported in several cohorts, and oligoclonal bands (OCBs) are rarely detected in the CSF of ADEM patients. 50-53) Sinclair et al. ${ }^{54)}$ analyzed OCBs in CSF from 200 children who underwent CSF investigations of their neurological condition and found intrathecal OCBs (those restricted to the CSF) in 11 of 58 (19\%) of those with inflammatory CNS disorders versus none of the 142 patients with noninflammatory CNS disorders. The authors concluded that OCBs are a useful but nonspecific biomarker of CNS inflammation of multiple causes. ${ }^{54)}$

In MS, LP is routinely performed to obtain supportive evidence of CNS inflammation. ${ }^{55)}$ In about $60 \%$ of pediatric patients with MS, routine analysis of CSF reveals normal findings. ${ }^{56)}$ The remainder of the patients had pleocytosis, elevated protein levels, increased IgGlevels, and OCBs. ${ }^{45}$ One study analyzed chemokine (C-X-C motif) ligand 13 (CXCL-13) levels in children with demyelinating disease and showed that $40 \%$ of ADEM, 22.2\% of clinically isolated syndrome, and $62.5 \%$ of MS children had high CXCL-13 levels versus noninflammatory controls. ${ }^{57}$

\section{CNS tumors}

Pediatric CNS tumors are the leading cause of cancer-related mortality in childhood. ${ }^{58)}$ The diagnosis of CNS tumors relies on biopsy of the tumor tissue and surgical intervention. ${ }^{59)}$ There is a need for less invasive methods to diagnose and characterize CNS tumors. Because of the blood-brain barrier, blood is not ideal for evaluating CNS tumors. ${ }^{60)}$ Moreover, blood is not a suitable for evaluating metastatic $\mathrm{CNS}$ tumors if the patients have coexisting systemic tumors. ${ }^{61)}$ In contrast to the blood, the CSF is in direct contact with the CNS and a suitable source of biomarkers from CNS tumors. ${ }^{60)}$

A number of tumor-derived biomarkers have been demonstrated in the CSF of adult patients with CNS tumors, including circulating tumor DNA (ctDNA), miRNA, and metabolites (Table 3) ${ }^{60,62)}$ However, only a few CSF biomarker studies have examined pediatric patients. Panditharatna et al. ${ }^{63)}$ identified
ctDNA H3K27M in the CSF and plasma of $88 \%$ of pediatric patients with diffuse midline glioma. The authors concluded that the CSF and plasma were appropriate for the detection of ctDNA and provided a molecularly based tool for tumor characterization. ${ }^{63)}$ One study analyzed protein expression levels of insulin-like growth factor (IGF) and IGF binding protein (IGFBP) in the CSF of pediatric medulloblastoma and ependymoma patients. ${ }^{64)}$ The IGF system plays a major role in regulating CNS development and is involved in the pathogenesis of brain tumors. ${ }^{65-68)}$ The IGFBP-3 levels were higher in pediatric medulloblastoma patients than in ependymoma patients and controls. ${ }^{64)}$ The authors suggested that the CSF IGFBP-3 level of medulloblastomas was a potential marker of residual disease. ${ }^{64)}$

A study of a cohort of 39 patients showed that the mean plasma and CSF osteopontin levels in atypical teratoid and rhabdoid tumors were higher than those in hydrocephalus, medulloblastoma, and epilepsy patients. ${ }^{69)}$ A primary CNS atypical teratoid rhabdoid tumor is an extremely malignant neoplasm in pediatric patients. ${ }^{70)}$ Osteopontin is a bone matrix glycoprotein that has a role in mineralization and bone resorption. ${ }^{71)}$ It also contributes to angiogenesis or neovascularization via the expression of vascular endothelial growth factor. ${ }^{71-73)}$ Varela et al. showed an association between monogenic amines in the ventricular CSF of pediatric patients with posterior fossa tumors. ${ }^{74}$

Biogenic amines including dopamine, epinephrine, norepinephrine, and serotonin are involved in the regulation of various neuronal functions, while changes in the monoamine levels of the CSF have been detected in multiple disorders. ${ }^{74,75)}$ They reported that the 3-methoxy-4-hydroxyphenylglycol level of the CSF was significantly higher in pediatric patients with astrocytoma than in those with medulloblastoma. ${ }^{74}$ A prospective clinical observational study demonstrated that children with newly diagnosed brain tumors exhibit markedly elevated CSF cleaved tau levels, which were suggestive of axonal damage. ${ }^{76}$ )

Prostaglandin D2 synthase (PGD2S) levels were six-fold lower

Table 3. Summary of pediatric novel CSF biomarkers of CNS tumors

\begin{tabular}{|c|c|c|c|c|}
\hline Biomarker & Source & Age & No. & Interpretation \\
\hline ctDNA H3K27M & Panditharatna et al. ${ }^{63)}$ & $4 y r-20 y r$ & 48 & $\begin{array}{l}\text { ctDNA H3K27M was identified in CSF and plasma in } 88 \% \text { of patients with diffuse } \\
\text { midline glioma. }\end{array}$ \\
\hline IGFBP-3 & de Bont et al. ${ }^{64)}$ & NA & 43 & $\begin{array}{l}\text { IGFBP-3 protein levels were higher in pediatric medulloblastoma patients than in } \\
\text { ependymoma patients and controls. }\end{array}$ \\
\hline Osteopontin & Kao et al. ${ }^{69)}$ & $0 y r-19.9 y r$ & 39 & $\begin{array}{l}\text { CSF osteopontin levels in patients with atypical teratoid/rhabdoid tumor were higher } \\
\text { than those in patients with medulloblastoma or no tumor. }\end{array}$ \\
\hline MHPG & Varela et al. ${ }^{74)}$ & $5.5 y r-15 y r$ & 22 & $\begin{array}{l}\text { The MHPG concentration in CSF was significantly higher in patients with astrocytomas } \\
\text { compared with patients with medulloblastomas. }\end{array}$ \\
\hline C-tau & Cengiz et al. ${ }^{76)}$ & $1 \mathrm{yr}-18 \mathrm{yr}$ & 15 & $\begin{array}{l}\text { CSF C-tau levels in children with brain tumors exhibit markedly elevated CSF C-tau } \\
\text { levels, suggesting axonal damage. }\end{array}$ \\
\hline PGD2S & Rajagopal et al. ${ }^{\text {77) }}$ & NA & 33 & $\begin{array}{l}\text { Levels of PGD2S were found to be } 6 \text { fold decreased in the pediatric tumor samples } \\
\text { versus control samples. }\end{array}$ \\
\hline Apo A-\| & de Bont et al. ${ }^{79)}$ & Median $7.2 \mathrm{yr}$ & 102 & Apolipoprotein A-II is highly overexpressed in CSF of pediatric brain tumor patients. \\
\hline bFGF & Li et al. ${ }^{82)}$ & $3 y r-20 y r$ & 44 & $\begin{array}{l}\text { bFGF was detected in the CSF of } 62 \% \text { patients with brain tumors but in none of the } \\
\text { controls. }\end{array}$ \\
\hline
\end{tabular}

CSF, cerebrospinal fluid; CNS, central nervous system; ctDNA, circulating tumor DNA; H3K27M, histone 3 p.K27M; IGFBP-3, insulin-like growth factor binding protein-3; MHPG, 3-methoxy-4-hydroxyphenylglycol; C-tau, cleaved tau; NA, not available; PGD2S, prostaglandin D2 synthase; Apo A-II, apolipoprotein A-Il; bFGF, basic fibroblast growth factor. 
in the pediatric tumor samples versus control samples in study by Rajagopal et al. ${ }^{77)}$ The authors speculated that the reduction is a host response to the presence of the tumor. ${ }^{77)} \mathrm{PGD} 2 \mathrm{~S}$ is a glycoprotein that is abundant in the CSF and is synthesized and secreted by both glial cells and the choroid plexus. ${ }^{78)}$ De Bont et al. ${ }^{79)}$ showed that apolipoprotein A-II (APO A-II) was highly overexpressed in the CSF of pediatric brain tumor patients, which is most likely is associated with a disrupted blood-brain barrier. APO A-II is the second most abundant human high-density lipoprotein apolipoprotein and synthesized predominantly in the liver. ${ }^{80)} \mathrm{APO}$ A-II is known to influence the metabolism of high-density lipoprotein and glucose and was recently linked to malignancies. ${ }^{81)}$ The CSF level of basic fibroblast growth factor (bFGF) was also increased in pediatric patients with brain tumors. ${ }^{82)}$ Moreover, bFGF is a widely distributed angiogenic molecule, and most cells produce it or have receptors for it. ${ }^{83)}$

\section{Hypoxic-ischemic encephalopathy}

Hypoxic-ischemic encephalopathy (HIE) contributes to world- wide major perinatal mortality and long-term disability in neonates. ${ }^{84)}$ In neonates with HIE, CSF levels of neuron-specific enolase (NSE) have been shown to play an important role as a marker of brain damage extent and enabled the prediction of the outcomes of infants with HIE in the prehypothermia era (Table 4). ${ }^{85-89)}$ NSE is a glycolytic enzyme, and structural damage to neuronal cells causes leakage of NSE into the extracellular compartment. ${ }^{90)}$ Interlukin-6, neurofilament protein, GFAP, and protein S-100 are known to be associated with neonatal HIE. ${ }^{85}$, 88) Therapeutic hypothermia appears to lower CSF NSE levels in infants with HIE; however, the predictive value of CSF NSE for neurodevelopmental impairment at 12 months of age is not affected by cooling. ${ }^{91)}$ One study showed that CSF levels of NSE predicted brain damage severity in newborns with hypothermiatreated HIE. ${ }^{92)}$ Increased CSF levels of activin A were detected in term neonates with perinatal asphyxia, and the highest concentrations were found among neonates with the most severe HIE. ${ }^{93)}$ Activin $\mathrm{A}$ is a member of the transforming growth factor-beta family, and it enhanced expression is known to represent a com-

Table 4. Summary of pediatric novel CSF biomarkers for HIE

\begin{tabular}{|c|c|c|c|c|}
\hline Biomarker & Source & Age & No. & Interpretation \\
\hline \multirow[t]{5}{*}{ NSE } & Tekgul et al. ${ }^{85)}$ & 1 day-3 day & 21 & $\begin{array}{l}\text { CSF NSE was significantly higher in infants with moderate to severe HIE as compared } \\
\text { with the mild HIE. }\end{array}$ \\
\hline & Ezgu et al. ${ }^{86)}$ & 1 day-3 day & 26 & CSF NSE levels of HIE group were higher than the control group. \\
\hline & Garcia-Alix et al. ${ }^{87)}$ & 1 day-3 day & 69 & Infants with HIE had highest CSF concentration of NSE \\
\hline & Blennow et al. ${ }^{88)}$ & 1 day-4 day & 30 & CSF NSE was increased in asphyxiated infants. \\
\hline & Thornberg et al. ${ }^{89)}$ & 1 day-4 day & 31 & NSE in CSF correlated with the degree of asphyxial damage. \\
\hline IL-6 & Tekgul et al. ${ }^{85)}$ & 1 day-3 day & 21 & $\begin{array}{l}\text { The CSF IL-6 levels were higher in infants with moderate to severe HIE when compared } \\
\text { with infants with mild HIE. }\end{array}$ \\
\hline NFp, GFAP, S-100 & Blennow et al. ${ }^{88)}$ & 1 day-4 day & 30 & NFp, GFAP, S-100 was increased in the CSF of asphyxiated infants. \\
\hline Activin A & Florio et al. $^{93)}$ & 0 day $-24 \mathrm{hr}$ & 30 & $\begin{array}{l}\text { CSF activin A were higher in the infants who developed severe HIE than in those who did } \\
\text { not or in controls. }\end{array}$ \\
\hline
\end{tabular}

CSF, cerebrospinal fluid; HIE, hypoxic-ischemic encephalopathy; NSE, neuron-specific enolase; IL-6, interleukin-6; CNS, central nervous system; NFp, neurofilament protein; GFAP, glial fibrillary acidic protein.

Table 5. Summary of pediatric novel CSF biomarkers for TBI

\begin{tabular}{|c|c|c|c|c|}
\hline Biomarker & Source & Age & No. & Interpretation \\
\hline P-selectin & Whalen et al. ${ }^{95)}$ & $2 \mathrm{mo}-16 \mathrm{yr}$ & 43 & P-selectin was increased in children with TBI versus meningitis and control. \\
\hline $\mathrm{S} 100 \beta, \mathrm{LL}-6$ & Shore et al. ${ }^{96)}$ & $2 \mathrm{mo}-15 \mathrm{yr}$ & 19 & $\begin{array}{l}\text { Compared to continuous CSF drainage, intermittent drainage of CSF was } \\
\text { associated with 2-fold greater CSF concentrations of s100B and IL-6. }\end{array}$ \\
\hline \multirow[t]{2}{*}{ NSE } & Shore et al. ${ }^{96)}$ & $2 \mathrm{mo}-15 \mathrm{yr}$ & 19 & $\begin{array}{l}\text { Compared to continuous CSF drainage, intermittent drainage of CSF was } \\
\text { associated with 2-fold greater CSF concentrations of NSE. }\end{array}$ \\
\hline & Chiaretti et al. ${ }^{99)}$ & $1 \mathrm{yr}-15 \mathrm{yr}$ & 32 & Early NSE concentrations correlated significantly with the severity of head injury. \\
\hline \multirow[t]{2}{*}{ VEGF } & Shore et al. ${ }^{96)}$ & $2 \mathrm{mo}-15 \mathrm{yr}$ & 19 & $\begin{array}{l}\text { Compared to continuous CSF drainage, intermittent drainage of CSF was } \\
\text { associated with 2-fold greater CSF concentrations of VEGF. }\end{array}$ \\
\hline & Shore et al. ${ }^{97)}$ & $0 \mathrm{yr}-15 \mathrm{yr}$ & 19 & Mean VEGF levels were increased after TBI versus control. \\
\hline $\begin{array}{l}\text { IL-1 } \beta, \text { IL-8, IL-10, IL-12P70, } \\
\quad \text { MIP-1a }\end{array}$ & Buttram et al. ${ }^{98)}$ & $1 \mathrm{mo}-16 \mathrm{yr}$ & 36 & IL-1 $\beta, I L-8, I L-10, I L-12 P 70$, MIP-1a were increased after TBI compared to controls \\
\hline NGF, DCX & Chiaretti et al. ${ }^{99)}$ & $1 \mathrm{yr}-15 \mathrm{yr}$ & 32 & $\begin{array}{l}\text { Early NGF and DCX concentrations correlated significantly with the severity of } \\
\text { head injury. }\end{array}$ \\
\hline $\begin{array}{l}\text { miR-182-5p, miR-221-3p, } \\
\text { miR-26b-5p, miR-320c } \\
\text { miR-29c-3p, miR-30e-5p }\end{array}$ & Hicks et al. ${ }^{100)}$ & $1 \mathrm{yr}-17 \mathrm{yr}$ & 10 & Childhood TBI described 6 parallel changes of miRNA in both CSF and saliva. \\
\hline
\end{tabular}


mon response to acute neuronal damage of various origins. ${ }^{94)}$

\section{Traumatic brain injury}

In one study, the levels of platelet selectin (P-selectin), an adhesion molecule associated with ischemia and reperfusion, were elevated in pediatric patients' CSF with TBI versus those with meningitis or controls (Table 5). ${ }^{95)}$ Increased blood-brain barrier permeability may contribute to the increased CSF P-selectin levels of pediatric patients with TBI. ${ }^{95)}$ Platelets are a major source of P-selectin; therefore, hemorrhage might cause the elevated P-selectin level in the CSF of TBI patients. ${ }^{95)}$ Shore et al. ${ }^{96}$ ) reported that, compared to continuous CSF drainage, intermittent drainage of the CSF was associated with 2-fold greater CSF concentrations of NSE, s100B, interleukin (IL)-6, and vascular endothelial growth factor (VEGF). ${ }^{96)}$ CSF VEGF levels were increased after TBI versus control in another study. ${ }^{97)}$ VEGF is known to be neuroprotective in several experimental brain injury models, and its levels are increased in the brain after TBI in humans and experimental animals. ${ }^{97)}$ CSF levels of cytokines such as IL-1 $\beta$, IL-8, IL-10, IL-12P70, and macrophage inflammatory protein-1 alpha were also increased after TBI compared to controls in another study. ${ }^{98)}$ Early nerve growth factor and doublecortin concentrations also seemed to be correlated with TBI severity. ${ }^{99)}$

An miRNA study of the CSF and saliva after childhood TBI described 6 parallel changes in miRNA (miR-182-5p, miR-2213p, miR-26b-5p, miR-320c, miR-29c-3p, and miR-30e-5p) in both. ${ }^{100)}$

\section{Intraventricular hemorrhage}

Intraventricular hemorrhage (IVH) has a high risk of neonatal mortality and later neurodevelopmental impairment in preterm infants. ${ }^{101)}$ One study analyzed proinflammatory cell-free miRNA levels in the CSF of 47 preterm infants with grade III or IV IVH versus controls and reported that the levels of miR-223, miR155, miR-181b, miR-126, and IL-8 were elevated in the CSF after the onset of IVH versus controls (Table 6). ${ }^{101)}$ The authors claimed that hemorrhage-induced CSF miRNA levels reflected inflammatory conditions as potential biomarkers in cases of preterm IVH. ${ }^{101)}$

\section{Congenital hydrocephalus}

The variety of etiologies of pediatric hydrocephalus creates additional complexities in biomarker analyses. ${ }^{9)}$ A recent study of the CSF of infants with untreated congenital hydrocephalus showed a significant increase in CSF amyloid precursor protein (APP) (Table 6). ${ }^{102)}$ In this study, CSF levels of APP and its derivative isoforms sAPP $\alpha, s A P P \beta, A \beta 42$, tau, phosphorylated tau, L1 neural cell adhesion molecule, and neural cell adhesion molecule but not aquaporin 4 or total protein were increased in untreated congenital hydrocephalus, particularly in children $\leq 1$ year of age, and CSF sAPP $\alpha$ levels showed the strongest relationship with congenital hydrocephalus. ${ }^{102)} \mathrm{AAP}$ is released in the setting of axonal injury, and hydrocephalus-related ventriculomegaly causes axonal pathology. ${ }^{103)}$ In addition, APP and its derivative isoforms are trophic factors with important roles in synaptogenesis and other aspects of neurodevelopment. ${ }^{104)}$

\section{Challenges of identifying CSF biomarkers in pediatric neurologic disorders}

Due to the difficulty acquiring a healthy child's CSF, only CSF from different conditions could be controls in CSF biomarker studies in pediatric disorders. Heterogeneity of pediatric neurological disorders is also a challenge for developing a CSF biomarker, and the fact that there are no reference values for many biomarkers in different age ranges, it is difficult to identify CSF biomarkers in children. Large-scale multi-institutional CSF studies, including network repositories, are needed to address these challenges. Advances in laboratory techniques that minimize the amount of CSF needed to analyze biomarkers should help in the development of CSF biomarkers for pediatric neurological disorders.

\section{Conclusion}

In pediatric neurological disorders, several promising CSF biomarkers that may be used to diagnose and monitor the effects of therapy. Although significant progress has been made in identifying CSF biomarkers of pediatric neurologic disorders, no single pathognomonic novel biomarkers are available for any pediatric neurologic disorders. Due to the complexity of pediatric neurological disorders and difficulty acquiring CSF from pediatric patients, identifying CSF biomarkers is challenging. Proper CSF laboratory standardization should be performed, and large-scale investigations should be performed to overcome these challenges.

See the commentary on "Cerebrospinal fluid biomarkers

Table 6. Summary of pediatric novel CSF biomarkers of IVH and congenital hydrocephalus

\begin{tabular}{|c|c|c|c|c|c|}
\hline Condition & Biomarker & Source & Age & No. & Interpretation \\
\hline $\mathrm{IVH}$ & $\begin{array}{l}\text { IL-8, miR-223, miR-155, } \\
\text { miR-81b, miR-126 }\end{array}$ & Fejes et al. ${ }^{101)}$ & NA & 61 & $\begin{array}{l}\text { Levels of IL-8, miR-223, miR-155, miR-181b, and miR-126 } \\
\text { was elevated in CSF after the onset of IVH in preterm infants. }\end{array}$ \\
\hline $\begin{array}{l}\text { Congenital } \\
\text { hydrocephalus }\end{array}$ & $\begin{array}{l}\text { APP, tau, pTau, L1CAM, } \\
\text { NCAM-1 }\end{array}$ & Limbrick Jr et al. $^{102)}$ & $\begin{array}{l}0 \text { mo-12 yr } 3 \\
\text { mo }\end{array}$ & 20 & $\begin{array}{l}\text { CSF levels of APP, tau, pTau, L1CAM, and NCAM-1 were } \\
\text { increased in congenital hydrocephalus. }\end{array}$ \\
\hline
\end{tabular}

CSF, cerebrospinal fluid; IVH, intraventricular hemorrhage; IL-8, interleukin-8; miR, microRNA; NA, not available; APP, amyloid precursor protein; pTau, phosphorylated tau; L1CAM, L1 neural cell adhesion molecule; NCAM-1, neural cell adhesion molecule. 
in various pediatric neurologic diseases" via https://oi.org/ 10.3345/cep.2021.01445.

\section{Footnotes}

Conflicts of interest: No potential conflict of interest relevant to this article was reported.

\section{ORCID:}

Seh Hyun Kim @ http://orcid.org/0000-0001-8686-1909

Soo Ahn Chae @ http://orcid.org/0000-0002-9825-8194

\section{References}

1. Shahim P, Mansson JE, Darin N, Zetterberg H, Mattsson N. Cerebrospinal fluid biomarkers in neurological diseases in children. Eur J Paediatr Neurol 2013;17:7-13.

2. Headache Classification Committee of the International Headache Society (IHS) The International Classification of Headache Disorders, 3rd edition. Cephalalgia 2018;38:1-211.

3. Avery RA. Interpretation of lumbar puncture opening pressure measurements in children. J Neuroophthalmol 2014;34:284-7.

4. Janssens E, Aerssens P, Alliet P, Gillis P, Raes M. Post-dural puncture headaches in children. A literature review. Eur J Pediatr 2003;162:117-21.

5. Nakajima M, Miyajima M, Ogino I, Akiba C, Sugano H, Hara T, et al. Cerebrospinal fluid biomarkers for prognosis of long-term cognitive treatment outcomes in patients with idiopathic normal pressure hydrocephalus. J Neurol Sci 2015;357:88-95.

6. Laitera T, Kurki MI, Pursiheimo JP, Zetterberg H, Helisalmi S, Rauramaa T, et al. The expression of transthyretin and amyloid-beta protein precursor is altered in the brain of idiopathic normal pressure hydrocephalus pa. tients. J Alzheimers Dis 2015;48:959-68.

7. Marklund N, Farrokhnia N, Hanell A, Vanmechelen E, Enblad P, Zetterberg $\mathrm{H}$, et al. Monitoring of beta-amyloid dynamics after human traumatic brain injury. J Neurotrauma 2014;31:42-55.

8. Steinacker P, Fang L, Kuhle J, Petzold A, Tumani H, Ludolph AC, et al. Soluble beta-amyloid precursor protein is related to disease progression in amyotrophic lateral sclerosis. PLoS One 2011;6:e23600.

9. Limbrick DD Jr, Castaneyra-Ruiz L, Han RH, Berger D, McAllister JP, Morales DM. Cerebrospinal fluid biomarkers of pediatric hydrocephalus. Pediatr Neurosurg 2017;52:426-35.

10. Zorofchian S, Iqbal F, Rao M, Aung PP, Esquenazi Y, Ballester LY. Circulating tumour DNA, microRNA and metabolites in cerebrospinal fluid as biomarkers for central nervous system malignancies. J Clin Pathol 2019; 72:271-80.

11. van den Berg MMJ, Krauskopf J, Ramaekers JG, Kleinjans JCS, Prickaerts J, Briede JJ. Circulating microRNAs as potential biomarkers for psychiatric and neurodegenerative disorders. Prog Neurobiol 2020;185:101732.

12. Takousis P, Sadlon A, Schulz J, Wohlers I, Dobricic V, Middleton L, et al. Differential expression of microRNAs in Alzheimer's disease brain, blood, and cerebrospinal fluid. Alzheimers Dement 2019;15:1468-77.

13. Goh SY, Chao YX, Dheen ST, Tan EK, Tay SS. Role of MicroRNAs in Parkinson's disease. Int J Mol Sci 2019;20:5649.

14. Raoof R, Jimenez-Mateos EM, Bauer S, Tackenberg B, Rosenow F, Lang $\mathrm{J}$, et al. Cerebrospinal fluid microRNAs are potential biomarkers of temporal lobe epilepsy and status epilepticus. Sci Rep 2017;7:3328.

15. Fire A, Xu S, Montgomery MK, Kostas SA, Driver SE, Mello CC. Potent and specific genetic interference by double-stranded RNA in Caenorhabditis elegans. Nature 1998;391:806-11.

16. Bartel DP. MicroRNAs: target recognition and regulatory functions. Cell 2009;136:215-33.
17. Wang Z. MicroRNA: a matter of life or death. World J Biol Chem 2010;1: 41-54.

18. Chen X, Ba Y, Ma L, Cai X, Yin Y, Wang K, et al. Characterization of microRNAs in serum: a novel class of biomarkers for diagnosis of cancer and other diseases. Cell Res 2008;18:997-1006.

19. Mitchell PS, Parkin RK, Kroh EM, Fritz BR, Wyman SK, Pogosova-Agadjanyan EL, et al. Circulating microRNAs as stable blood-based markers for cancer detection. Proc Natl Acad Sci US A 2008;105:10513-8.

20. Sheinerman KS, Umansky SR. Circulating cell-free microRNA as biomarkers for screening, diagnosis and monitoring of neurodegenerative diseases and other neurologic pathologies. Front Cell Neurosci 2013;7:150.

21. Bonadio WA. The cerebrospinal fluid: physiologic aspects and alterations associated with bacterial meningitis. Pediatr Infect Dis J 1992;11:423-31.

22. Bonadio W. Pediatric lumbar puncture and cerebrospinal fluid analysis. J Emerg Med 2014;46:141-50.

23. Statz A, Felgenhauer K. Development of the blood-CSF barrier. Dev Med Child Neurol 1983;25:152-61.

24. Rosenling T, Slim CL, Christin C, Coulier L, Shi S, Stoop MP, et al. The effect of preanalytical factors on stability of the proteome and selected metabolites in cerebrospinal fluid (CSF). J Proteome Res 2009;8:5511-22.

25. Teunissen CE, Petzold A, Bennett JL, Berven FS, Brundin L, Comabella M, et al. A consensus protocol for the standardization of cerebrospinal fluid collection and biobanking. Neurology 2009;73:1914-22.

26. Mattsson N, Savman K, Osterlundh G, Blennow K, Zetterberg H. Converging molecular pathways in human neural development and degeneration. Neurosci Res 2010;66:330-2.

27. Cameron S, Gillio-Meina C, Ranger A, Choong K, Fraser DD. Collection and analyses of cerebrospinal fluid for pediatric translational research. Pediatr Neurol 2019;98:3-17.

28. Morris M, Maeda S, Vossel K, Mucke L. The many faces of tau. Neuron 2011;70:410-26.

29. Tanuma N, Miyata R, Kumada S, Kubota M, Takanashi J, Okumura A, et al. The axonal damage marker tau protein in the cerebrospinal fluid is increased in patients with acute encephalopathy with biphasic seizures and late reduced diffusion. Brain Dev 2010;32:435-9.

30. Gurnett CA, Landt M, Wong M. Analysis of cerebrospinal fluid glial fibrillary acidic protein after seizures in children. Epilepsia 2003;44:1455-8.

31. Medana IM, Idro R, Newton CR. Axonal and astrocyte injury markers in the cerebrospinal fluid of Kenyan children with severe malaria. J Neurol Sci 2007;258:93-8.

32. Bignami A, Eng LF, Dahl D, Uyeda CT. Localization of the glial fibrillary acidic protein in astrocytes by immunofluorescence. Brain Res 1972;43: 429-35.

33. Kristjansdottir R, Uvebrant P, Rosengren L. Glial fibrillary acidic protein and neurofilament in children with cerebral white matter abnormalities. Neuropediatrics 2001;32:307-12.

34. Barger SW, Van Eldik LJ, Mattson MP. S100 beta protects hippocampal neurons from damage induced by glucose deprivation. Brain Res 1995; 677:167-70.

35. Kim SH, Yun SW, Kim HR, Chae SA. Exosomal microRNA expression profiles of cerebrospinal fluid in febrile seizure patients. Seizure 2020;81: 47-52.

36. Li ZY, Dang D, Wu H. Next-generation sequencing of cerebrospinal fluid for the diagnosis of unexplained central nervous system infections. Pediatr Neurol 2021;115:10-20.

37. Molero-Luis M, Casas-Alba D, Orellana G, Ormazabal A, Sierra C, Oliva $\mathrm{C}$, et al. Cerebrospinal fluid neopterin as a biomarker of neuroinflamma. tory diseases. Sci Rep 2020;10:18291.

38. Dale RC, Brilot F, Fagan E, Earl J. Cerebrospinal fluid neopterin in paediatric neurology: a marker of active central nervous system inflammation. Dev Med Child Neurol 2009;51:317-23.

39. Molero-Luis M, Fernandez-Urena S, Jordan I, Serrano M, Ormazabal A, Garcia-Cazorla A, et al. Cerebrospinal fluid neopterin analysis in neuropediatric patients: establishment of a new cut off-value for the identification of inflammatory-immune mediated processes. PLoS One 2013;8:e 83237.

40. Ghisoni K, Martins Rde P, Barbeito L, Latini A. Neopterin as a potential 
cytoprotective brain molecule. J Psychiatr Res 2015;71:134-9.

41. Macdonald-Laurs E, Koirala A, Britton PN, Rawlinson W, Hiew CC, McRae J, et al. CSF neopterin, a useful biomarker in children presenting with influenza associated encephalopathy? Eur J Paediatr Neurol 2019; 23:204-13.

42. Casas-Alba D, Valero-Rello A, Muchart J, Armangue T, Jordan I, Cabrerizo $\mathrm{M}$, et al. Cerebrospinal fluid neopterin in children with enterovirus-related brainstem encephalitis. Pediatr Neurol 2019;96:70-3.

43. Yamanaka G, Ishii C, Kawashima H, Oana S, Miyajima T, Hoshika A. Cerebrospinal fluid Diacron-Reactive Oxygen Metabolite levels in pediatric patients with central nervous system diseases. Pediatr Neurol 2008; 39:80-4.

44. Shahim P, Darin N, Andreasson U, Blennow K, Jennions E, Lundgren J, et al. Cerebrospinal fluid brain injury biomarkers in children: a multicenter study. Pediatr Neurol 2013;49:31-9.e2.

45. Pohl D, Rostasy K, Reiber H, Hanefeld F. CSF characteristics in early-onset multiple sclerosis. Neurology 2004;63:1966-7.

46. Pan D, Pan M, Xu YM. Mir-29a expressions in peripheral blood mononuclear cell and cerebrospinal fluid: diagnostic value in patients with pediatric tuberculous meningitis. Brain Res Bull 2017;130:231-5.

47. Pohl D, Alper G, Van Haren K, Kornberg AJ, Lucchinetti CF, Tenembaum $S$, et al. Acute disseminated encephalomyelitis: updates on an inflammatory CNS syndrome. Neurology 2016;87:S38-45.

48. Hung PC, Wang HS, Chou ML, Lin KL, Hsieh MY, Wong AM. Acute disseminated encephalomyelitis in children: a single institution experience of 28 patients. Neuropediatrics 2012;43:64-71.

49. Leake JA, Albani S, Kao AS, Senac MO, Billman GF, Nespeca MP, et al. Acute disseminated encephalomyelitis in childhood: epidemiologic, clinical and laboratory features. Pediatr Infect Dis J 2004;23:756-64.

50. Tenembaum S, Chamoles N, Fejerman N. Acute disseminated encephalomyelitis: a long-term follow-up study of 84 pediatric patients. Neurology 2002;59:1224-31.

51. Alper G, Heyman R, Wang L. Multiple sclerosis and acute disseminated encephalomyelitis diagnosed in children after long-term follow-up: comparison of presenting features. Dev Med Child Neurol 2009;51:480-6.

52. Pavone P, Pettoello-Mantovano M, Le Pira A, Giardino I, Pulvirenti A, Giugno R, et al. Acute disseminated encephalomyelitis: a long-term prospective study and meta-analysis. Neuropediatrics 2010;41:246-55.

53. Erol I, Ozkale Y, Alkan O, Alehan F. Acute disseminated encephalomyelitis in children and adolescents: a single center experience. Pediatr Neurol 2013;49:266-73.

54. Sinclair AJ, Wienholt L, Tantsis E, Brilot F, Dale RC. Clinical association of intrathecal and mirrored oligoclonal bands in paediatric neurology. Dev Med Child Neurol 2013;55:71-5.

55. Waldman A, O'Connor E, Tennekoon G. Childhood multiple sclerosis: a review. Ment Retard Dev Disabil Res Rev 2006;12:147-56.

56. Duquette P, Murray TJ, Pleines J, Ebers GC, Sadovnick D, Weldon P, et al. Multiple sclerosis in childhood: clinical profile in 125 patients. J Pediatr 1987;111:359-63.

57. Galardi M, Butler R, Lui A, Cole J, Mikesell R, Salter A, et al. Cerebrospinal fluid (CSF) neurofilament and CXCL-13 levels in children with demyelinating disease (P2.307). Neurology 2018;90(15 Supplement): P2.307.

58. Ostrom QT, Gittleman H, Truitt G, Boscia A, Kruchko C, Barnholtz-Sloan JS. CBTRUS statistical report: primary brain and other central nervous system tumors diagnosed in the United States in 2011-2015. Neuro Oncol 2018;20:iv1-86.

59. Tang K, Gardner S, Snuderl M. The role of liquid biopsies in pediatric brain tumors. J Neuropathol Exp Neurol 2020;79:934-40.

60. Haber DA, Gray NS, Baselga J. The evolving war on cancer. Cell 2011; 145:19-24.

61. Pan W, Gu W, Nagpal S, Gephart MH, Quake SR. Brain tumor mutations detected in cerebral spinal fluid. Clin Chem 2015;61:514-22.

62. Weston CL, Glantz MJ, Connor JR. Detection of cancer cells in the cerebrospinal fluid: current methods and future directions. Fluids Barriers CNS 2011;8:14.

63. Panditharatna E, Kilburn LB, Aboian MS, Kambhampati M, Gordish-
Dressman $\mathrm{H}$, Magge $\mathrm{SN}$, et al. Clinically relevant and minimally invasive tumor surveillance of pediatric diffuse midline gliomas using patientderived liquid biopsy. Clin Cancer Res 2018;24:5850-9.

64. de Bont JM, van Doorn J, Reddingius RE, Graat GH, Passier MM, den Boer ML, et al. Various components of the insulin-like growth factor system in tumor tissue, cerebrospinal fluid and peripheral blood of pediatric medulloblastoma and ependymoma patients. Int J Cancer 2008;123:594600.

65. van Doorn J, Gilhuis HJ, Koster JG, Wesseling P, Reddingius RE, Gresnigt MG, et al. Differential patterns of insulin-like growth factor-I and -II mRNA expression in medulloblastoma. Neuropathol Appl Neurobiol 2004;30:503-12.

66. Russo VC, Gluckman PD, Feldman EL, Werther GA. The insulin-like growth factor system and its pleiotropic functions in brain. Endocr Rev 2005;26:916-43.

67. Samani AA, Yakar S, LeRoith D, Brodt P. The role of the IGF system in cancer growth and metastasis: overview and recent insights. Endocr Rev 2007;28:20-47.

68. Zumkeller W. IGFs and IGF-binding proteins as diagnostic markers and biological modulators in brain tumors. Expert Rev Mol Diagn 2002;2: 473-7.

69. Kao CL, Chiou SH, Ho DM, Chen YJ, Liu RS, Lo CW, et al. Elevation of plasma and cerebrospinal fluid osteopontin levels in patients with atypical teratoid/rhabdoid tumor. Am J Clin Pathol 2005;123:297-304.

70. Buchino JJ. Atypical teratoid/rhabdoid tumor--a stereogram unveiled. Adv Anat Pathol 1999;6:97-102.

71. Furger KA, Menon RK, Tuck AB, Bramwell VH, Chambers AF. The functional and clinical roles of osteopontin in cancer and metastasis. Curr Mol Med 2001;1:621-32.

72. Hirama M, Takahashi F, Takahashi K, Akutagawa S, Shimizu K, Soma S, et al. Osteopontin overproduced by tumor cells acts as a potent angiogenic factor contributing to tumor growth. Cancer Lett 2003;198:107-17.

73. Shijubo N, Uede T, Kon S, Nagata M, Abe S. Vascular endothelial growth factor and osteopontin in tumor biology. Crit Rev Oncog 2000;11:13546.

74. Varela M, Alexiou GA, Liakopoulou M, Papakonstantinou E, Pitsouni D, Alevizopoulos GA. Monoamine metabolites in ventricular CSF of children with posterior fossa tumors: correlation with tumor histology and cognitive functioning. J Neurosurg Pediatr 2014;13:375-9.

75. Scheinin M. Monoamine metabolites in human cerebrospinal fluid: indicators of neuronal activity? Med Biol 1985;63:1-17.

76. Cengiz P, Zemlan F, Eickhoff JC, Ellenbogen R, Zimmerman JJ. Increased cerebrospinal fluid cleaved tau protein (C-tau) levels suggest axonal damage in pediatric patients with brain tumors. Childs Nerv Syst 2015;31: 1313-9.

77. Rajagopal MU, Hathout Y, MacDonald TJ, Kieran MW, Gururangan S, Blaney SM, et al. Proteomic profiling of cerebrospinal fluid identifies prostaglandin D2 synthase as a putative biomarker for pediatric medulloblastoma: a pediatric brain tumor consortium study. Proteomics 2011; 11:935-43.

78. Yamashima T, Sakuda K, Tohma Y, Yamashita J, Oda H, Irikura D, et al. Prostaglandin D synthase (beta-trace) in human arachnoid and meningioma cells: roles as a cell marker or in cerebrospinal fluid absorption, tumorigenesis, and calcification process. J Neurosci 1997;17:2376-82.

79. de Bont JM, den Boer ML, Reddingius RE, Jansen J, Passier M, van Schaik $\mathrm{RH}$, et al. Identification of apolipoprotein A-II in cerebrospinal fluid of pediatric brain tumor patients by protein expression profiling. Clin Chem 2006;52:1501-9.

80. Martin-Campos JM, Escola-Gil JC, Ribas V, Blanco-Vaca F. Apolipoprotein A-II, genetic variation on chromosome 1q21-q24, and disease susceptibility. Curr Opin Lipidol 2004;15:247-53.

81. Tailleux A, Duriez P, Fruchart JC, Clavey V. Apolipoprotein A-II, HDL metabolism and atherosclerosis. Atherosclerosis 2002;164:1-13.

82. Li VW, Folkerth RD, Watanabe H, Yu C, Rupnick M, Barnes P, et al. Microvessel count and cerebrospinal fluid basic fibroblast growth factor in children with brain tumours. Lancet 1994;344:82-6.

83. Moscatelli D. High and low affinity binding sites for basic fibroblast growth 
factor on cultured cells: absence of a role for low affinity binding in the stimulation of plasminogen activator production by bovine capillary endothelial cells. J Cell Physiol 1987;131:123-30.

84. Bonifacio SL, deVries LS, Groenendaal F. Impact of hypothermia on predictors of poor outcome: how do we decide to redirect care? Semin Fetal Neonatal Med 2015;20:122-7.

85. Tekgul H, Yalaz M, Kutukculer N, Ozbek S, Kose T, Akisu M, et al. Value of biochemical markers for outcome in term infants with asphyxia. Pediatr Neurol 2004;31:326-32.

86. Ezgu FS, Atalay Y, Gucuyener K, Tunc S, Koc E, Ergenekon E, et al. Neuron-specific enolase levels and neuroimaging in asphyxiated term new. borns. J Child Neurol 2002;17:824-9.

87. Garcia-Alix A, Cabanas F, Pellicer A, Hernanz A, Stiris TA, Quero J. Neuron-specific enolase and myelin basic protein: relationship of cerebrospinal fluid concentrations to the neurologic condition of asphyxiated full-term infants. Pediatrics 1994;93:234-40.

88. Blennow M, Savman K, Ilves P, Thoresen M, Rosengren L. Brain-specific proteins in the cerebrospinal fluid of severely asphyxiated newborn infants. Acta Paediatr 2001;90:1171-5.

89. Thornberg E, Thiringer K, Hagberg H, Kjellmer I. Neuron specific enolase in asphyxiated newborns: association with encephalopathy and cerebral function monitor trace. Arch Dis Child Fetal Neonatal Ed 1995;72:F3942.

90. Bandyopadhyay S, Hennes H, Gorelick MH, Wells RG, Walsh-Kelly CM. Serum neuron-specific enolase as a predictor of short-term outcome in children with closed traumatic brain injury. Acad Emerg Med 2005;12: 732-8.

91. Sun J, Li J, Cheng G, Sha B, Zhou W. Effects of hypothermia on NSE and S-100 protein levels in CSF in neonates following hypoxic/ischaemic brain damage. Acta Paediatr 2012;101:e316-20.

92. Leon-Lozano MZ, Arnaez J, Valls A, Arca G, Agut T, Alarcon A, et al. Cerebrospinal fluid levels of neuron-specific enolase predict the severity of brain damage in newborns with neonatal hypoxic-ischemic encephalopathy treated with hypothermia. PLoS One 2020;15:e0234082.

93. Florio P, Luisi S, Bruschettini M, Grutzfeld D, Dobrzanska A, Bruschettini $\mathrm{P}$, et al. Cerebrospinal fluid activin a measurement in asphyxiated full-term newborns predicts hypoxic ischemic encephalopathy. Clin Chem 2004; 50:2386-9.

94. Florio P, Gazzolo D, Luisi S, Petraglia F. Activin A in brain injury. Adv Clin Chem 2007;43:117-30.

95. Whalen MJ, Carlos TM, Kochanek PM, Wisniewski SR, Bell MJ, Carcillo $\mathrm{JA}$, et al. Soluble adhesion molecules in CSF are increased in children with severe head injury. J Neurotrauma 1998;15:777-87.

96. Shore PM, Thomas NJ, Clark RS, Adelson PD, Wisniewski SR, Janesko $\mathrm{KL}$, et al. Continuous versus intermittent cerebrospinal fluid drainage after severe traumatic brain injury in children: effect on biochemical markers. J Neurotrauma 2004;21:1113-22.

97. Shore PM, Jackson EK, Wisniewski SR, Clark RS, Adelson PD, Kochanek PM. Vascular endothelial growth factor is increased in cerebrospinal fluid after traumatic brain injury in infants and children. Neurosurgery 2004;5 4:605-11; discussion 11-2.

98. Buttram SD, Wisniewski SR, Jackson EK, Adelson PD, Feldman K, Bayir $\mathrm{H}$, et al. Multiplex assessment of cytokine and chemokine levels in cerebrospinal fluid following severe pediatric traumatic brain injury: effects of moderate hypothermia. J Neurotrauma 2007;24:1707-17.

99. Chiaretti A, Barone G, Riccardi R, Antonelli A, Pezzotti P, Genovese O, et al. NGF, DCX, and NSE upregulation correlates with severity and outcome of head trauma in children. Neurology 2009;72:609-16.

100. Hicks SD, Johnson J, Carney MC, Bramley H, Olympia RP, Loeffert $\mathrm{AC}$, et al. Overlapping microRNA expression in saliva and cerebrospinal fluid accurately identifies pediatric traumatic brain injury. J Neurotrauma 2018;35:64-72.

101. Fejes Z, Erdei J, Pocsi M, Takai J, Jeney V, Nagy A, et al. Elevated proinflammatory cell-free MicroRNA levels in cerebrospinal fluid of premature infants after intraventricular hemorrhage. Int J Mol Sci 2020;21: 6870.

102. Limbrick DD Jr, Baksh B, Morgan CD, Habiyaremye G, McAllister JP 2nd, Inder TE, et al. Cerebrospinal fluid biomarkers of infantile congenital hydrocephalus. PLoS One 2017;12:e0172353.

103. Yuan W, McKinstry RC, Shimony JS, Altaye M, Powell SK, Phillips JM, et al. Diffusion tensor imaging properties and neurobehavioral outcomes in children with hydrocephalus. AJNR Am J Neuroradiol 2013;34:43945.

104. Dawkins E, Small DH. Insights into the physiological function of the beta-amyloid precursor protein: beyond Alzheimer's disease. J Neurochem 2014;129:756-69.

How to cite this article: Kim SH, Chae SA. Promising candidate cerebrospinal fluid biomarkers of seizure disorder, infection, inflammation, tumor, and traumatic brain injury in pediatric patients. Clin Exp Pediatr 2022;65:56-64. https://doi. org/10.3345/cep.2021.00241 